\title{
Surgical treatment of cervical kyphosis
}

\author{
Ke Han $\cdot$ Chang Lu $\cdot$ Jing Li $\cdot$ Guang-Zhong Xiong $\cdot$ \\ Bing Wang $\cdot$ Guo-Hua Lv $\cdot$ You-Wen Deng
}

Received: 27 May 2010/Revised: 30 August 2010/Accepted: 29 September 2010/Published online: 22 October 2010

(C) Springer-Verlag 2010

\begin{abstract}
Cervical kyphosis is an uncommon but potentially debilitating and challenging condition. We reviewed the etiology, presentation, clinical and radiological evaluation, and treatment of cervical kyphosis. Based on the current controversy as to the ideal mode of surgical management, we paid particular attention to the available surgical strategies. There are three approaches for cervical kyphosis: the anterior, posterior or combined procedures. The principal indication for the posterior strategy is a flexible kyphosis or kyphosis caused by ankylosing spondylitis. The main point of debate is between the choice of the anterior or the combined strategy. The two strategies were compared with regard to clinical outcome, correction of deformity, rate of fusion, complications, revision surgery, and mortality. The combined strategy appears to result in a greater degree of correction than the anterior-alone strategy, and it is more likely to improve the cervical alignment to achieve a lordosis. However, the procedure carries a higher rate of postoperative neurological deterioration, complications, revision surgery, and mortality. Although the anterioralone strategy achieves a smaller reduction of cervical kyphosis, it has a lower rate of postoperative neurological deterioration, complications, revision surgery, and mortality. We recommend that the surgical treatment of cervical kyphosis should be planned on an individual basis. A multicenter, prospective, randomized controlled study would be necessary to determine the ideal mode of treatment for complex cervical kyphosis.
\end{abstract}

\footnotetext{
K. Han · C. Lu · J. Li ( $₫)$ - G.-Z. Xiong · B. Wang ·

G.-H. Lv · Y.-W. Deng

Department of Spinal Surgery, Second Xiangya Hospital,

Central South University, Renmin Road 139\#,

Changsha 410011, Hunan Province, China

e-mail: xyspine@126.com
}

Keywords Cervical kyphosis - Kyphotic deformity Surgical treatment $\cdot$ Correction $\cdot$ Cervical spine

$\begin{array}{ll}\text { Abbreviations } \\ \text { VB } & \text { Vertebral body } \\ \text { VBs } & \text { Vertebral bodies } \\ \text { PLK } & \text { Postlaminectomy kyphosis } \\ \text { CK } & \text { Cervical kyphosis } \\ \text { CKD } & \text { Cervical kyphotic deformity }\end{array}$

\section{Introduction}

Cervical kyphotic deformity (CKD) is a potentially debilitating condition. Treatment of cervical kyphosis (CK) is a challenge to the spinal surgeon and the ideal mode of surgical correction remains controversial. There are three surgical strategies for CK: the anterior, posterior and combined procedures. The main point of debate is the choice between the anterior and the combined procedures. Some surgeons [16, 20, 21, 44, 56, 66] prefer the anterior-alone approach because they are familiar with the procedure and it permits both ventral decompression, as the spinal cord compression in CK is usually ventral, and the correction of deformity. It is associated with lower rates of morbidity and mortality than the combined approach. Other surgeons [37, 39, 41] prefer the combined anterior and posterior approach rather than the anterior procedure alone, as the latter may fail to achieve large correction and is prone to reconstructive failure and loss of correction due to mechanical disadvantages, especially in patients with postlaminectomy kyphosis (PLK). 
All previous studies with regard to $\mathrm{CK}$ had a retrospective design, with all of the inherent weaknesses of such studies. However, it is difficult to complete a large, multicenter, prospective, randomized controlled study, which would help to determine the ideal mode of treatment for complex CK, due to the relative rarity of this condition. Recently, one study reviewed the outcomes of patients who underwent corrective surgery for cervicothoracic kyphosis secondary to ankylosing spondylitis [12]. Another study systematically reviewed the literature to assess the longterm outcomes of patients who underwent corrective surgery for subaxial CK due to different causes [13]. No study has reviewed the treatment for CK caused by factors other than ankylosing spondylitis.

The purpose of this study was to review the recent literature with special attention to the surgical treatment of CK that was caused by factors other than ankylosing spondylitis, in an attempt to clarify the optimal choice of surgical management.

The normal alignment of the cervical spine is with lordosis, which develops as infants learn to support their own head. However, there is no clear and unequivocal definition of a normal cervical lordosis. Gore et al. [19] observed a lordosis from $\mathrm{C} 2$ to $\mathrm{C} 7$ in patients with osteoarthritis of between $16^{\circ}$ and $22^{\circ}$ in men and between $15^{\circ}$ and $25^{\circ}$ in women. However, the normal range of this degree varies according to the measurement scheme used. In normal cervical lordosis, the cervical load-bearing axis lies posterior to the vertebral bodies (VBs) of C2-C7. VBs that primarily resist compressive forces bear approximately $36 \%$ of the axial load. Posterior natural structures that resist tensile forces bear approximately $64 \%$ of the axial load [43]. The balance between both elements maintains the normal cervical curvature and maintains the head in an upright position. Any disruption of this balance will lead to a sagittal abnormality, which most commonly presents as a kyphotic deformity [40,55]. CK shifts the load axis in the anterior direction and the axial load shared by the anterior column of the cervical spine increases, which results in a potential wedge deformation of the VBs and discs and the consequent progression of kyphosis. Application of the axial load in CK may also cause the progression of kyphosis through a moment arm-induced bending moment [6]. That is, the so-called "kyphosis begets kyphosis".

\section{Etiology of CK}

CK may develop secondary to advanced degenerative disease, trauma, neoplastic disease, infection, systemic arthritides, such as ankylosing spondylitis or rheumatoid arthritis, and iatrogenic processes [2, 57]; the latter are the most common. CK may also be idiopathic (Fig. 1).

The most common iatrogenic cause is secondary to surgery [2]. Ventrally, CK may be due to a pseudarthrosis or any failure to restore the normal cervical lordosis during surgery $[9,18,66]$; dorsally, the disruption of cervical natural stabilizing structures, such as tension band which is composed of the interspinous ligaments, ligamenta flava, laminae and facet joint complexes [2, 8, 17, 55], may lead to CK. Another important iatrogenic etiological factor is radiotherapy, which is particularly important in children. The kyphosis in this instance may result from impairment of bone growth due to radiation [28, 42, 49].

PLK is the most common postsurgical deformity [2]. The incidence of PLK is as high as $21 \%$ in patients who have undergone laminectomy for cervical spondylotic myelopathy [25], but varies widely depending on the age of the individual, preoperative degree of the loss of lordosis, preoperative spinal stability, presence of an intramedullary tumor and the extent, number and location of laminectomies and facetectomies [3, 5, 20, 25, 26, 31, 36, 54, 63, 64].

Pediatric patients and young adults are more prone to developing CK after cervical laminectomy [5, 63] because of their ongoing spinal growth, the laxity of spinal ligaments [45, 63], the more horizontal orientation of the facet complex and the poor resistance of incompletely ossified VBs to compressive loads [62] (Fig. 2). The reported
Fig. 1 A 17-year-old female had a idiopathic cervical kyphosis as shown by the preoperative lateral radiography (a). The spinal cord was draped over the apex of the kyphotic deformity (b). She underwent anterior discectomy and fusion combined with posterior fixation using lateral mass screws. She achieved a neutral alignment postoperatively (c) and solid fusion 4 months postoperatively (d)
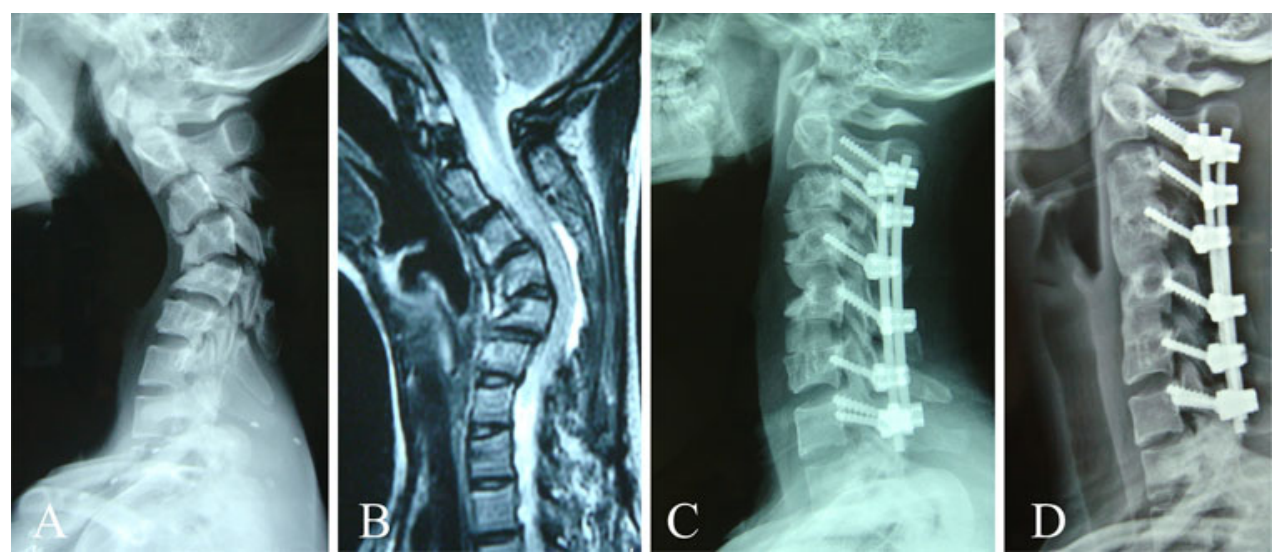
Fig. 2 The initial preoperative MRI of a 15-year-old female showed an intradural extramedullary tumor and preexisting deformity of the cervical spine (a). She developed a severe cervical kyphosis $\left(78^{\circ}\right)(\mathbf{b}, \mathbf{c}, \mathbf{d})$ (later images taken when the patient was 23 years old) after she underwent cervical

laminectomies for the tumor. She also had a quadriplegia over a period of 8 years. She underwent a $720^{\circ}$ (anteriorposterior-anterior-posterior) fusion with instrumentation under a single anesthetic. She was able to walk unassisted 1 month after surgery. The angle of kyphosis was $46^{\circ}$ immediately after surgery (e), and there was no loss of correction during the 3-year follow-up period (f). A solid fusion was achieved (f) and the spinal cord was significantly decompressed $(\mathbf{d}, \mathbf{g})$
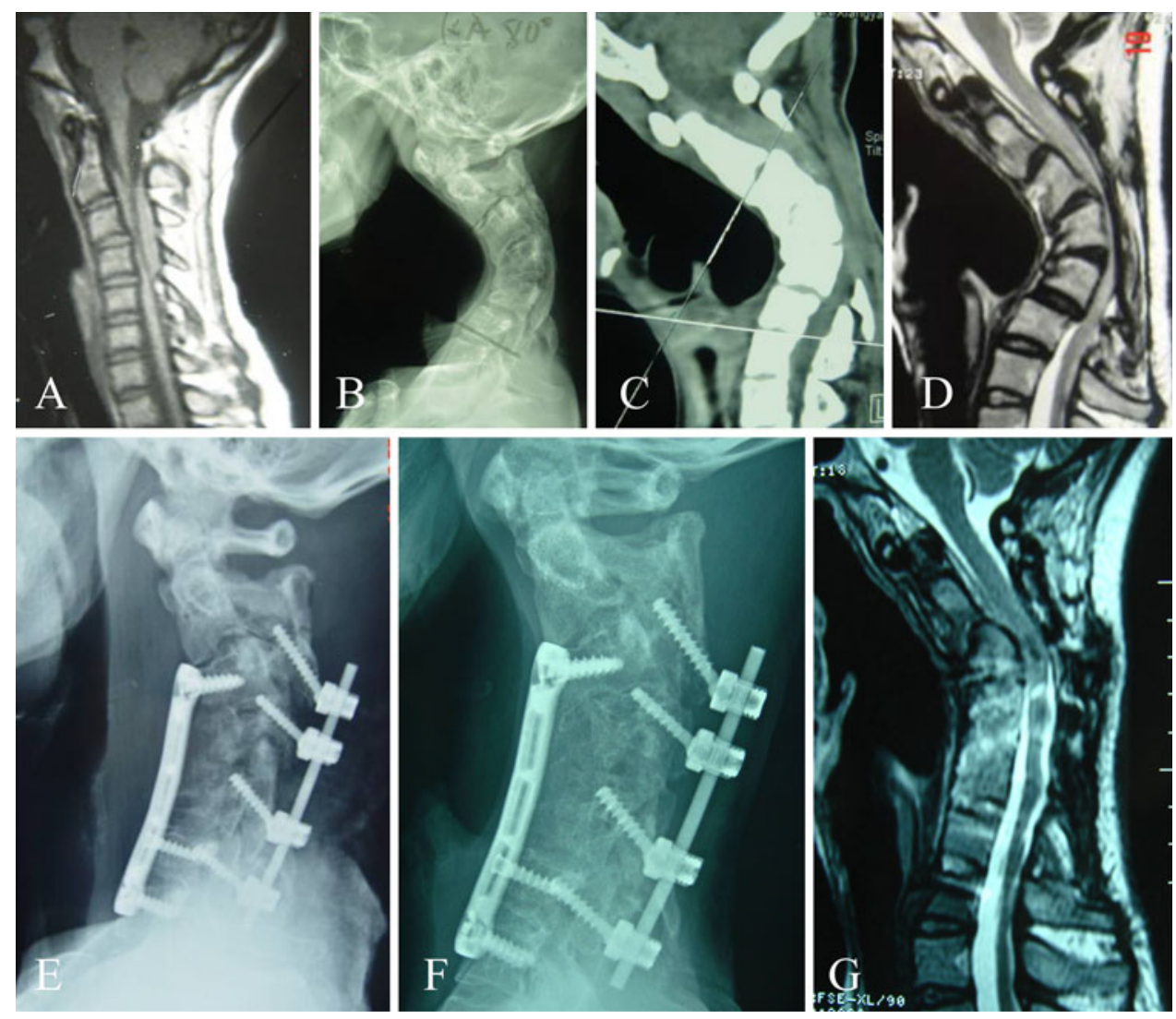

incidences range from 9 to $100 \%[5,14,21,26,30,31,34$, 63]. PLK is not common in adults because their cervical spine may have already been partially fused. However, if the patients present with kyphosis or instability preoperatively, their problems may be aggravated by laminectomy $[20,25,36]$.

The presence of a spinal cord tumor is an independent condition that causes kyphotic deformity [31, 54], which may be due to muscle denervation and weakness caused by the involvement of the anterior horn cells $[11,54]$ and/or a flexed posture that opens the spinal canal in an attempt to relieve the symptoms [14]. Many authors reported that the high rate of pediatric patients with an intramedullary tumor had preexisting spinal deformities preoperatively [31, 59] (Fig. 2a).

Additionally, the laminectomy of $\mathrm{C} 2$ and/or C7, the multilevel removal of laminae and any significant removal of facet joints may increase the risk of postoperative deformities, although studies that investigate this question have been inconclusive [3, 26, 40, 64].

Therefore, posterior instrumentation and spinal fusion may be recommended in patients with such factors that predispose them to immediate postoperative instability to prevent PLK. However, serious consideration should be given to performing a concomitant posterior arthrodesis due to the procedure-related risks, including the failure of instrumentation or the accelerated degeneration of adjacent levels [10, 22]. In the experience of Sciubba et al. [52], patients with an intradural cervical tumor may benefit from concomitant spinal fusion after cervical laminectomy when preexisting myelopathic motor symptoms are present or when they need to undergo the removal of laminae at three or more levels. Laminoplasty may also be a prophylactic option [40], despite the fact that a high rate of deformities after laminoplasty was reported in a meta-analysis [46]. Additionally, we should perform a careful follow-up for years postoperatively to screen for kyphosis in patients who undergo laminectomy without fusion, according to the individual risk factors in each case.

\section{Presentation}

Patients with CK often present with neck pain, neurological deficits, such as myelopathy, radiculopathy, quadriparesis, quadriplegia and Brown-Séquard syndrome [16]. Severe kyphosis may adversely affect forward vision, swallowing and respiration because of the settling of the chin onto the chest [4]. Lumbar hyperlordosis may coexist to compensate for severe $\mathrm{CK}$, and such patients often complain of low back pain due to subsequent lumbar degeneration. 
The cervical musculature is placed at a significant biomechanical disadvantage in $\mathrm{CK}$ and requires constant contraction to maintain an upright head posture [38]. This is one reason for the neck pain. The excessive, accelerated degeneration of cervical intervertebral discs may also contribute to neck pain [27].

Neurological deficits may be due to stenosis of the central canal and/or neuroforamina, which results from advanced degenerative changes in the kyphotic cervical spine. The spinal cord may be "draped" over the dorsal aspect of the VBs at the apex of the kyphotic deformity, in the so-called "bowstring effect" (Figs. 1b, 2d); the cord shifts anteriorly to the anterior portion of the spinal canal and becomes tethered by the dentate ligaments with the progression of $\mathrm{CK}$. Increased mechanical stress on the spinal cord may result in microvascular compression and ischemia [7, 32, 60]. Chronic impairment of the microcirculatory flow in the spinal cord may result in myelomalacia and spinal cord atrophy. Shimizu et al. [53] discovered a decrease in the vascular distribution on the ventral side of the compressed spinal cord, as well as demyelination of nerve fibers in the funiculi and neuronal loss in the anterior horns in an animal model with CKD. Additionally, there may be repetitive trauma to the spinal cord with normal cervical flexion/extension in CK. All of the above contribute to neurological deficits.

\section{Clinical and radiological evaluation}

It is important that all patients are evaluated clinically and radiologically. Clinical evaluation includes history and physical examination, neurological function, and neck pain, along with any other relevant symptoms. Neurological function is usually evaluated with the modified Japanese Orthopedic Association Myelopathy (mJOA) score [16], Frankel grading [1], and the Nurick scale [65]. The mJOA score provides a more comprehensive measurement of myelopathy than the Frankel score. Therefore, most authors now often use the mJOA score to quantify motor, sensory and urinary function. The Nurick scale is often used to quantify ambulatory function. The status of patients after surgery is graded as excellent, good, fair or poor based on the Odom criteria [66], or classified as worse, unchanged, improved or resolved [56]. The present pain intensity score is used to assess neck pain [16]. The neck disability index (NDI) and visual analog scale (VAS) are used to assess clinical outcomes for neck and arm pain [44].

Patients should be evaluated by cervical X-rays (anteroposterior and lateral plain radiographs, dynamic radiographs, standing anteroposterior and lateral long-cassette radiographs), computerized tomography (CT) scans and magnetic resonance imaging (MRI) before and after surgery and during the follow-up period. Lateral plain radiography is used to measure the sagittal angle and any other abnormalities. The sagittal angle can be measured locally or regionally [16]; the local sagittal angle involves the diseased segment and the regional angle involves the area from $\mathrm{C} 2$ to $\mathrm{C} 7$. Some authors measure the Ishihara index [37]. Dynamic radiographs permit the assessment of spinal flexibility as well as any occult instability or subluxation of the kyphotic cervical spine. The diagnosis of pseudarthrosis may be established by a combination of plain and dynamic radiographs. Standing long-cassette radiographs permit the assessment of the overall sagittal balance of the spine [41]. Thin-cut CT scanning is used to identify the presence of ankylosis in the anterior column and/or posterior facet joints, the accuracy of implant placement and any fusion or pseudarthrosis of grafts. CK can be categorized as a flexible or fixed kyphosis [41]. If dynamic flexion-extension radiographs demonstrate a reduction of deformity of less than $50 \%$ and thin-cut CT scans demonstrate segmental ankylosis, the $\mathrm{CK}$ will be defined as fixed kyphosis. MRI scans permit the evaluation of compression to the spinal cord and nerve roots. If a cerebrospinal fluid signal is present dorsal to the VBs on a T2-weighted sagittal MRI scan, these are usually deemed to be intermediate VBs that may be retained to provide intermediate points of implant fixation during the anterior reconstruction procedure [57]. Iwasaki et al. [23] were able to predict the progression of myelopathy related to kyphosis with the use of the ratio of the anteroposterior diameter between the spinal cord at the apex and the medullopontine junction on MRI. A ratio below 0.3 is a risk factor for cervical myelopathy.

\section{Management}

Treatment options for $\mathrm{CK}$ include conservative and surgical treatments. Conservative treatment [17], which is mainly used to address the symptoms and consequences of pain, includes physical therapy, chiropractic care, cervical traction, brace therapy, nonsteroidal anti-inflammatory agents and steroid injections.

The indications for surgical treatment of CK are not well defined. Surgical treatment may be indicated in patients with neurological compromise, severe mechanical pain, progressive kyphotic deformity or disability, including dysphagia or difficulty with forward gaze. The goals of surgery should be neural decompression, correction of the deformity and spinal stabilization with fusion. The outcomes of the three approaches to treat CK (anterior, posterior and combined) are compared in Tables 1,2 and 3.

Traction is often used prior to surgical intervention. If the reduction of kyphosis is significant after 5-7 days of 
Table 1 Summary of clinical studies with regard to the surgical treatment of cervical kyphosis (demographic data)

\begin{tabular}{|c|c|c|c|c|c|c|}
\hline Authors & Main correction strategy & No. of patients & Mean age (years) & Male/female & Follow-up & Study type \\
\hline Zdeblick et al. [65] & Ventral & 14 & 46 & $11 / 3$ & 27.9 months & Retrospective \\
\hline Zdeblick et al. [66] & Ventral & 8 & 50 & $4 / 4$ & 46.3 months & Retrospective \\
\hline Riew et al. [48] & Ventral & 18 & 54 & $11 / 7$ & 2.7 years & Retrospective \\
\hline Herman et al. [21] & Ventral & 20 & 58 & $14 / 6$ & 27.6 months & Retrospective \\
\hline Gülmen et al. [20] & Ventral & 4 & 30 & Not known & 1.7 years & Retrospective \\
\hline Ferch et al. [16] & Ventral & 28 & 57 & $17 / 11$ & 25 months & Retrospective \\
\hline Steinmetz et al. [56] & Ventral & 12 & 40 & $7 / 3$ & 9 months & Retrospective \\
\hline Park et al. [44] & Ventral & 23 & 56 & $16 / 7$ & 44.5 months & Retrospective \\
\hline Mummaneni et al. [37] & Combined & 30 & 56 & $16 / 14$ & 2.6 years & Retrospective \\
\hline O’Shaughnessy et al. [41] & Combined & 20 & 52 & $9 / 7$ & 4.5 years & Retrospective \\
\hline Nottmeier et al. [39] & Combined & 41 & 61 & $20 / 21$ & 19 months & Retrospective \\
\hline Abumi et al. [1] & Dorsal/combined & 30 & 47 & $17 / 13$ & 42 months & Retrospective \\
\hline Total & & 248 & & & & \\
\hline
\end{tabular}

Table 2 Summary of clinical studies with regard to surgical treatment of cervical kyphosis (clinical outcome)

\begin{tabular}{|c|c|}
\hline Authors & Clinical outcome \\
\hline Zdeblick et al. [65] & $\begin{array}{l}\text { No patient lost neural function. Nurick scores improved from } 3.6 \text { points before operation to } 1.3 \\
\text { points at follow-up. Of four patients unable to walk before surgery, one remained unchanged, } \\
\text { one was able to walk with a cane, and two could walk independently }\end{array}$ \\
\hline Zdeblick et al. [66] & Six patients had excellent results, one had a good result, and one patient had a poor result \\
\hline Riew et al. [48] & $\begin{array}{l}\text { Twelve patients improved neurologically by at least one Nurick grade and none of the patients } \\
\text { worsened neurologically. Nurick grade improved from } 3.1 \text { preoperatively to } 2 \text { postoperatively }\end{array}$ \\
\hline Herman et al. [21] & $\begin{array}{l}\text { Two patients had complete resolution of symptoms; } 11 \text { patients had substantial improvement } \\
\text { in pain and neurological function; } 6 \text { patients had pain improvement but neurological persistence; } \\
1 \text { had initial neurological improvement but progression of pain and neurological function at follow-up }\end{array}$ \\
\hline Gülmen et al. [20] & $\begin{array}{l}\text { One patient died of respiratory complications } 20 \text { days after surgery; two patients with tetraparesis } \\
\text { improved significantly; the neck pain in one patient resolved completely } 1 \text { month after surgery }\end{array}$ \\
\hline Ferch et al. [16] & $\begin{array}{l}\text { Myelopathy scores improved in } 11 \text { patients, remained stable in } 15 \text { patients and deteriorated in } 1 \text { patient. } \\
\text { Cervical pain scores were similar before and after surgery }\end{array}$ \\
\hline Steinmetz et al. [56] & All patients improved postoperatively; three patients had complete resolution of their symptoms \\
\hline Park et al. [44] & $\begin{array}{l}\text { Nurick grades improved from } 2.52 \text { to } 1.04 \text {; VAS scores improved from } 6.22 \text { to } 2.30 \text {; the neck disability } \\
\text { index improved from } 27.09 \text { to } 10.48 \text {. Nine patients had complete resolution of symptoms; } \\
\text { all patients achieved neurological improvements of at least one or more Nurick grades }\end{array}$ \\
\hline Mummaneni et al. [37] & $\begin{array}{l}\text { Nurick scores improved from } 3.2 \text { to } 1.3 \text {; the mJOA scores improved from } 10.5 \text { to } 15 \text {. None of the } \\
\text { surviving patients worsened neurologically after the surgery }\end{array}$ \\
\hline $\begin{array}{l}\text { O'Shaughnessy } \\
\text { et al. [41] }\end{array}$ & $\begin{array}{l}\text { Nurick classification score improved from } 2.4 \text { before surgery to } 1.5 \text { after surgery. In terms of Odom criteria, } \\
\text { six patients had excellent result; eight had good result; there was one fair and one poor result. With regard to } \\
\text { postoperative swallowing function, nine had no difficulty; six had minor difficulty and one had major difficulty }\end{array}$ \\
\hline Nottmeier et al. [39] & Preoperative symptoms were improved in 39 patients; unchanged in 1 patient and worsened in 1 patient \\
\hline Abumi et al. [1] & $\begin{array}{l}\text { Of the } 24 \text { patients with myelopathy before surgery, } 3 \text { obtained a two-grade improvement of Frankel grading, } \\
11 \text { patients obtained one grade, and } 10 \text { patients were unchanged }\end{array}$ \\
\hline
\end{tabular}

traction, a dorsal strategy that includes fixation and fusion is often used to maintain the correction. If there is no reduction of kyphosis after 7 days of traction, it is unlikely to achieve success with traction. Traction may also be associated with medical complications, transient neurological deterioration or patient refusal [21]. Occasionally, traction is continued into the operating room and used to correct the deformity during the operation. In the anterior 


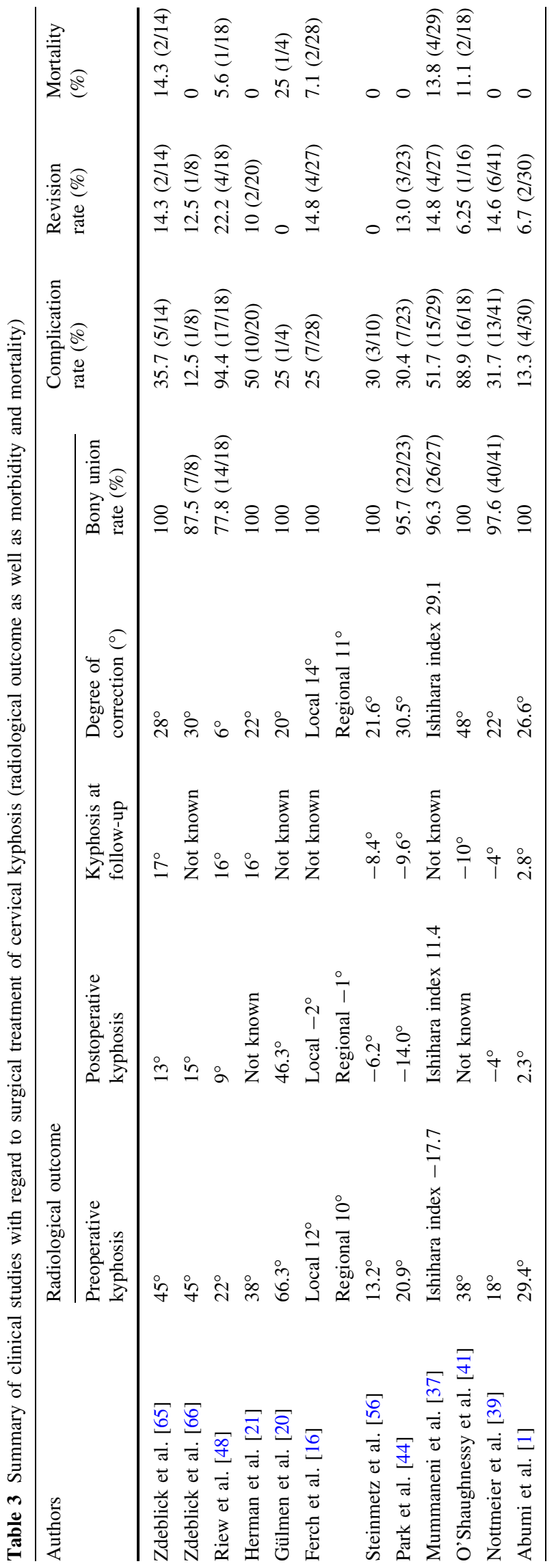

procedure, once decompression is completed, the amount of traction is increased to correct the deformity [65].

Vocal cord function should be analyzed by laryngoscopy before an anterior approach is undertaken in patients with prior anterior cervical surgery. Patients should be neuromonitored throughout the entire operative procedure with transcranial motor-evoked potentials (TcMEPs), somatosensory-evoked potentials (SSEPs) and electromyography.

\section{Anterior strategy}

This strategy may be indicated for a fixed CKD without posterior ankylosis of the facet joints. Many spinal surgeons choose an anterior or ventral approach because they are familiar with the procedure, which permits ventral decompression, correction of deformity and spinal reconstruction; additionally, it is associated with minimal morbidity. A review of the literature shows that the development of the anterior strategy was divided into three stages that were proposed between 1989 and 2010 [16, 20, 21, 44, 48, $56,65,66]$.

Prior to the establishment of modern-day techniques, surgeons initially utilized anterior corpectomies and arthrodesis without internal fixation for CK. Zdeblick et al. [65] reported a series of 14 patients with CK and myelopathy who were treated with these procedures. Correction was achieved by increasing intraoperative traction and extending the neck over a rolled sheet. However, follow-up showed that there was loss of $4^{\circ}$. A kyphosis of more than $20^{\circ}$ persisted in two patients, which may have been due to fusion of the facet joints or extension of the deformity into the thoracic spine. As described in that study, the ends of the graft were rounded off to fit into the rounded 3- to 4mm-deep crater in the end plates of the superior and inferior intact VBs. The grafts were locked into the crater under skull-tong traction to prevent their displacement. However, three patients had dislodged grafts despite the use of halo vests. Of note, two out of these three patients had also undergone a prior laminectomy, but immobilization in a halo vest was recommended to prevent graftrelated complications. Zdeblick et al. [66] treated patients who had undergone failure of anterior discectomy and arthrodesis with a repeat anterior decompression and autogenous grafting. Eight patients developed a kyphotic deformity due to the collapse of the grafts. After salvage surgery, all but one had excellent or good clinical result and reduction of the kyphosis. The exception had a fibrous non-union and a recurrence of myelopathy, and this patient underwent a reoperation. The authors implied that a repeat anterior arthrodesis without posterior augmentation might lead to a good outcome as well. After this study, Riew et al. [48] presented a series of patients who had undergone postlaminectomy $\mathrm{CK}$ and were treated with anterior 
cervical corpectomies and arthrodesis. They concentrated specifically on the complications that were associated with these procedures. Despite symptomatic improvement in most patients, only 8 out of 18 patients had a decreased degree of kyphosis. Furthermore, the kyphosis in three patients actually increased by more than $10^{\circ}$ due to subsidence of the fibular grafts. Additionally, they reported a complication rate related to surgery of more than $50 \%$, including extrusion or collapse of the graft, pseudarthrosis and progressive kyphosis. Compared with the previous study [65], they found that immobilization with a halo vest inadequately protected the patients from graft-related complications. The high rate of complications may have been due to the destabilization of the cervical spine. Anterior corpectomy in patients with PLK further disrupts the spinal ring. The left and right halves of the spine are only connected by soft tissue, and resistance to torsion and flexion-extension forces is substantially decreased. Anterior grafts without posterior elements are therefore the only structure that can resist axial loading, which may not be prevented by immobilization with the halo vest. Therefore, the risk of collapse or extrusion of graft increases [61]. The authors advocated augmentation of the construct with a posterior arthrodesis and instrumentation in patients who needed multilevel corpectomies and reconstruction after a previous laminectomy. In the series of 100 patients reported by McAfee et al. [33], a few cases with PLK were treated with a one-stage circumferential operation, which was believed to reduce the likelihood of perioperative complications. However, the necessity of exposing the unprotected posterior spinal cord and the risk of damaging important structures during surgery restrict its application.

With the development of the cervical plate and screw fixation system, anterior cervical plating was introduced as part of the anterior-only procedure for the correction of CK. Herman and Sonntag [21] had reported on the successful outcomes and lower complication rate of multilevel corpectomies or discectomies together with anterior cervical plating. They achieved a $20^{\circ}$ correction of the sagittal angle through intraoperative axial traction and distraction, and most of the complications in this cohort were not related to the operative technique. A screw became dislodged in one patient. There are two potential reasons for their low complication rate: the first is that most of the corpectomies included only one or two levels; secondly, the application of the anterior plate gave resistance to flexion, extension, rotation and laterally applied forces. However, anterior-only multilevel (three or more) corpectomies combined with plating may also be associated with a high rate of complications. Gülmen [20] reported four cases with PLK that were treated with anterior corpecto- mies or discectomies, fusion and plating. Although they did not achieve complete correction of kyphosis, three patients showed a significant clinical improvement. One patient died of respiratory complications. Ferch et al. [16] treated patients with CKD and myelopathy using the same procedures. Although a satisfactory correction of the kyphosis was achieved in the majority, only $41 \%$ of patients had an improvement in their myelopathy scores. They concluded that the correction of $\mathrm{CK}$ may assist in maximizing the chances of recovery of spinal cord function.

The combination of corpectomy and discectomy is another option. Corpectomy is only used at levels with retrovertebral compression and discectomy is used at other levels combined with segmental fixation including plate and multilevel screws [47]. This technique avoids consecutive corpectomies and a bridging implantation (an implantation with fixation only at the most rostral and caudal ends) allows multiple points of screw fixation through at least one intermediate VB and offers greater stability and multipoint bending force applications, particularly with regard to resistance to translation and rotation. Steinmetz et al. [56] concluded that the technique was safe and effective for the correction of postsurgical $\mathrm{CK}$, while avoiding dorsal fusion and instrumentation in the majority of cases. Deformity correction was achieved through four steps in the series: after the decompression had been completed, the doughnut underneath the head of the patient was removed to extend the cervical spine; posts that were placed in a convergent fashion were distracted, which provided superior surgical leverage; grafts that were fashioned in a trapezoidal manner were placed and the intermediate VB was "brought to the implant" as the screws on intervening VBs were tightened after the rostral and caudal screws were secured initially. However, this series only reported ten cases with a short duration of follow-up. A larger series with longer-term follow-up was presented by Park et al. [44], who suggested that anterior-alone surgical treatment with the use of hybrid decompression combined with multilevel instrumented fusions yielded acceptable clinical and neurological improvements and effective CK correction. They concluded that these techniques appeared to decrease the incidence of graft-related complications compared with previous reports. However, they augmented the construct with a posterior cervical arthrodesis and instrumentation in patients who required corpectomies at more than three levels for PLK and/or had poor bone quality. Although they believed that most of the complications in their series were not related to operative technique, $13 \%$ of patients had graft-related complications, including implant displacement, graft dislodgment and pseudarthrosis. 
Combined anterior and posterior strategy

A combined strategy may be indicated if dorsal spinal cord compression and/or facet joint ankylosis is present, or the correction of a deformity cannot be achieved using an anterior approach alone. Posterior arthrodesis and instrumentation have also been used to augment the construction in patients with significant unstable factors, such as threelevel corpectomies that were associated with laminectomy or poor bone quality $[44,65,66]$. The combined anterior and posterior approach allows for ventral and dorsal osteotomies and release, removes all compression to the spinal cord, effectively corrects the kyphosis through lengthening the anterior column and shortening the posterior column, and provides strong dorsal and ventral fixation, which may be helpful in resisting the translation and torsion of the spine, reducing graft-related complications, and increasing the fusion rate (Figs. 1, 2).

Zdeblick et al. [65] mainly reported their experience with the anterior-alone procedure for CK. They believed that cervical trauma was often associated with the disruption of posterior ligaments, which then did not heal and could be a major cause of development of kyphotic deformity. Therefore, four patients with prior traumatic injury were treated with a posterior arthrodesis and wire fixation in addition to the anterior decompression and grafting to prevent graft-related complications. However, wire fixation was shown to provide less rigidity than pedicle or lateral mass screw fixation [15]. Abumi et al. [1] treated patients having a fixed kyphosis with a combined anterior and posterior procedure. The correction of the kyphosis was achieved in all patients through posterior pedicle screw fixation, which provided a stronger stabilizing effect and greater pullout strength; however, there was greater risk associated with screw placement than with lateral mass screw fixation [24, 29]. All patients had solid bony unions. However, two patients had nerve root complications, of which one might be related to the placement of the pedicle screw. In the study by Schultz et al. [51], complex cervical spine disorders were addressed surgically with single-stage anterior-posterior decompression and reconstruction. A total of 34 patients had a kyphotic deformity that was either trauma related or postlaminectomy. Correction was achieved through distraction during the anterior procedure, and then the posterior procedure was performed for augmentation of the reconstruction. The combined approach was strongly considered in patients who underwent three or more corpectomies. Additionally, patients who suffered from comorbid conditions that could affect bone quality, such as smoking, diabetes, osteoporosis and renal dialysis, might be candidates for combined approach. They achieved good clinical and radiological outcomes with a low rate of graft-related complications and instrumentation failure. Mummaneni et al. [37] performed a circumferential fusion procedure for the treatment of CKD, which achieved dramatic corrections without new neurological deficits. However, there was a significant rate of morbidity and mortality in their series of 30 patients. Ten patients had major or minor complications and there were a total of four deaths. They indicated that their study was not intended to endorse a combined ventral and dorsal approach that was superior to ventral-alone or dorsal-alone approaches. Some authors preferred the circumferential strategy, because they believed that a single anterior procedure might fail to achieve a large correction and be prone to reconstruction failure and the loss of correction due to mechanical disadvantage, especially in patients with PLK. O'Shaughnessy et al. [41] treated patients with fixed CK and myelopathy using circumferential spinal osteotomies and instrumented reconstruction; they achieved excellent clinical and radiological outcomes along with maintenance of the correction. The instrumentation in their study consisted of lateral mass screws in the subaxial cervical spine, pars/pedicle screws at the level of C2 and pedicle screws or hooks in the thoracic spine. They believed that maintenance of the correction was due to use of posterior fixation at multiple points that extended from $\mathrm{C} 2$ to the upper thoracic spine, as well as the anterior interbody grafts despite no additional augmentation of the plating. They found that anterior plating was not necessary for stabilization and fusion when associated with a posterior solid fixation. There was a high rate of airway and swallowing dysfunction, which might have been related to the plate, although anterior plates were rarely used in this study. Four patients $(25 \%)$ underwent a gastrostomy and three patients (19\%) underwent a tracheostomy as a result. Nottmeier et al. [39] treated the patients with CKD with a $360^{\circ}$ approach. They achieved adequate correction of the deformity and maintenance of the correction. They subsequently proposed that patients with PLK, kyphosis that was adjacent to a previous $360^{\circ}$ procedure, traumatic kyphosis with significant ligamentous injury, multilevel corpectomies or risk factors for pseudoarthrosis, such as smoking, should be treated with a $360^{\circ}$ reconstruction. Although the rate of major complications was low in their study, there was a higher rate of adjacent segment kyphosis, which may be related to rigid fixations in these procedures.

\section{Sequence of combined procedure}

Deformity correction in the combined strategy was accomplished during either the anterior or posterior stage of the procedure. O'Shaughnessy et al. [41] reported that the deformity was corrected by a manual reduction; the secondary surgeon released the head of the patient from the operative table during the posterior stage. In this situation, 
surgeons preferred to perform posterior correction as the final stage, because the total cervical contour could be assessed and the laminae could be visualized directly. This enabled a judgment to be made of any segmental translation to avoid potential neural injury during the process of correction. Therefore, the most common sequence of correction is the anterior-posterior sequence, which means that anterior discectomies and osteotomies are performed followed by interbody grafting; subsequently, posterior instrumentation placement, osteotomies and correction are performed. Theoretically, the anterior grafts may loosen and migrate during the posterior correction. However, this situation has not been described in the study. Due to the concern that anterior grafts may become loose and migrate, the anterior-posterior-anterior sequence may be optimal, However, this sequence may increase the incidence of airway and swallowing complications. The posterioranterior-posterior sequence is used when the kyphosis is too severe to perform the anterior approach in the first stage. The posterior-anterior sequence is used in circumstances where there is no ankylosis of the anterior column of the cervical spine. The purpose of the anterior procedure in this instance is to reconstruct the load-bearing capability of the spine. In the study by Abumi et al. [1], the correction of kyphosis was achieved by loading a compressive force between the inserted pedicle screws in the posterior procedure after facetectomies or circumferential osteotomies were performed. Anterior grafting was performed as the final stage of the procedure based on the concern that the grafts may loosen if grafting was performed before posterior correction. Therefore, the anterior-posterior-anterior sequence was used in their study. The initial anterior procedure was performed for corpectomy and bilateral uncinectomy. Kyphosis correction was then achieved in the posterior procedure. The second anterior procedure was used for reconstruction of the anterior column. The anterior-posterior sequence was used in several patients with ventral compression; in these cases, anterior decompression was performed followed by posterior correction.

Another situation is in which correction is achieved in the anterior stage of the combined procedure with the aforementioned method of leverage; the goal of the posterior stage then includes decompression, release, instrumentation placement and arthrodesis. In this situation, anterior-posterior sequence is optimal (Fig. 1). Nottmeier et al. [39] treated the majority of their patients with this sequence. The first stage in their series included osteotomies, correction, placement of grafts and plating. Placement of posterior instrumentation and arthrodesis was performed in the second stage to augment construction. The posterior-anterior-posterior sequence may be used when posterior ankylosis is present: posterior release of the ankylosis is performed, followed by anterior decompression, correction and reconstruction. Finally, posterior instrumentation and fusion complete the procedure. In fact, such patients can be treated on occasion with the anterior-posterior sequence [58]. After ventral release and decompression, surgeons place a Cobb periosteal elevator into the intervertebral space and gently rotate it clockwise and counterclockwise. This performance may fracture the posterior ankylosed facet joints. A dorsal procedure to release the facet joints may be obviated.

\section{Posterior strategy}

A review of the literature shows that there were two situations in which CK was treated with a single dorsal procedure. Abumi et al. [1] utilized posteriorly placed cervical pedicle screw fixation to manage patients with flexible mild degenerative kyphosis. Although they achieved favorable results and no screw-related complications, the risks that were associated with placing the cervical pedicle screws limited the use of this strategy. Lateral mass screw fixations with minimal morbidity may also be used in this situation despite being biomechanically inferior to fixation with pedicle screws.

Another posterior approach, which uses the posterior cervical extension osteotomy technique to treat cases of CK caused by ankylosing spondylitis, has been described [4, 35]. Posterior extension osteotomy includes complete laminectomy of C7, partial laminectomies of C6 and T1, and the removal of the spinous process of C6, the ankylosed C7-T1 facet joints, and a portion of the C6 and T1 pedicles. After the osteotomy, deformity correction is achieved by extending the head under electrophysiological monitoring and the correction is maintained postoperatively in either a halo vest or with internal fixation. The procedure is often associated with a high incidence of morbidity.

\section{Extent of instrument and fusion}

The extent of instrumentation and fusion should be decided according to the etiology and location of the deformity, the quality of native bone and the extent of prior decompressive surgery. In general, the rostral and caudal instrumented VBs are the most rostral and caudal that are involved in the deformity curve [56]. There is often a compensatory exaggerated lordosis at the levels adjacent to the kyphosis rostrally and/or caudally. Therefore, an accelerated degeneration of adjacent disc spaces often coexists, which may be included in the extent of instrumentation and fusion. Sometimes, we extend the fixation length to between one and two levels of normal vertebrae above and below the deformity curve to acquire more 
intermediate points of fixation. This technique may facilitate the correction of kyphosis and the maintenance of the correction. Occasionally, surgeons have shown that patients with severe deformities had instrumentation placed more rostrally and/or caudally down to $\mathrm{C} 2$ and/or the upper thoracic spine with pedicle screws or hooks in the posterior procedure [41]. In the study by Nottmeier et al. [39], screws were placed into the occiput, pars or pedicle of $\mathrm{C} 2$, lateral masses of $\mathrm{C} 3-\mathrm{C} 6$, lateral mass or pedicle of $\mathrm{C} 7$, and the upper thoracic pedicles to achieve a long-level fixation in patients with severe deformities.

\section{Instrumentation}

Cervical plating systems, including rigid and dynamic implants, are often used in the anterior procedure. Some authors [56] have suggested using a dynamic ventral implant in the anterior procedure, which not only permits controlled subsidence and allows the graft to bear most of the axial load to promote bone fusion via Wolff's Law [6], but also decreases stresses at the screw-bone interface that may diminish the chance of fixation failure. However, young patients may not require a dynamic implant. It should be used in patients with pseudarthrosis related to a prior fusion attempt.

The posterior fixation system has developed from the lateral mass screw-plate system to the screw-rod system, which facilitates the transition from cervical to thoracic instrumentation [37, 39, 41, 51]. In some situations, the cervical pedicle screw fixation system is also used [1].

\section{Grafts}

Grafts that have been used in the correction of CK include autografts (tricortical iliac crest, fibula and sternum), allografts, titanium structural grafts and polyetheretherketone cages. A local autograft material or rh-BMP is often used to fill in allografts, titanium structural grafts and polyetheretherketone cages. However, the use of rh-BMP should not become routine because of the known associated complications. In patients with a previous pseudarthrosis, the use of autografts is optimal for further reconstruction. When the corpectomy is shorter, a graft from the iliac crest can be used. When the corpectomy is of a longer length, a fibular graft is used [21, 37, 41, 44, 48, 56, 66].

\section{Postoperative immobilization}

With the use of cervical internal fixation, most patients were only immobilized with a hard cervical collar for between 2 and 3 months after surgery [37]. Patients with occipitocervical or cervicothoracic fixations or osteoporosis were placed into a Philadelphia collar or a cervicothoracic orthosis $[1,39]$. The halo vest may be used in patients with osteoporotic bones, multilevel fusions or in the case of a previous fusion failure. The use of a halo apparatus should be individualized.

\section{Complications}

Complications related to the correction procedure include implant displacement, graft dislodgment, pseudarthrosis, dysphagia, hoarseness of voice, wound infection, dural tear resulting in cerebrospinal fluid leakage, pneumonia, neurological deficits (e.g., quadriparesis, radiculopathy and C5 root palsy) and injury to the vertebral artery. Airway and swallowing problems have been described after cervical anterior procedure, especially in patients who underwent multilevel corpectomies with a large degree of surgical exposure and a long operative time [50]. Airway and swallowing complications could be reduced by meticulous hemostasis, surgical drainage and leaving the patients intubated overnight in certain specific situations. Patients with transient dysphagia should receive enteral nutrition through a temporary nasoduodenal tube. Patients with dysphagia that persists for more than 7 days should receive nutrition via a percutaneous gastrostomy tube. Similarly, patients with dyspnea occasionally need a tracheostomy. C5 root palsies may be due to traction on the nerve root during the process of kyphosis correction.

\section{Which strategy should we choose?}

The ideal mode of surgical correction for CK remains controversial. Most surgeons have reached the consensus that patients with flexible CK should be treated with the posterior-alone procedure [1]. With regard to a fixed kyphosis, some surgeons $[16,20,21,44,56,66]$ prefer the anterior strategy over a combined procedure, which has higher morbidity and mortality rates. Other surgeons [37, $39,41]$ prefer the combined anterior and posterior strategy, as the anterior procedure is more likely to fail achieving a large correction and is prone to reconstruction failure, as well as loss of correction due to mechanical disadvantages, especially in patients with PLK.

In an attempt to clarify the controversy, we reviewed 12 studies in which a total of 248 patients had undergone a procedure for the correction of CK (Tables 1, 2, 3) [1, 16, 20, 21, 37, 39, 41, 44, 48, 56, 65, 66]. Five patients were lost to follow-up and six patients died before adequate follow-up could be completed [16, 20, 37, 41, 56]. These 
11 patients were excluded from the study. Therefore, 237 patients were included in the clinical and radiological study. There were six delayed deaths [16, 37, 48, 65], and the overall mortality encompassing all 248 patients was $4.8 \%$ (12/248). Ten patients $(10 / 237,4.2 \%)$ worsened neurologically after surgery $[1,16,21,39,41]$. All studies with the exception of one, which used the Ishihara index [37], quantified the sagittal alignment with the use of the sagittal angle. Based on 11 studies that included 210 patients $[1,16,20,21,39,41,44,48,56,65,66]$, the mean degree of preoperative kyphosis was $26.2^{\circ}$. The mean postoperative kyphosis was $2.4^{\circ}$, and the mean correction angle was $23.8^{\circ}$.

There were 99 complications in 243 patients $(99 / 243$, 40.7\%) [1, 16, 20, 21, 37, 39, 41, 44, 48, 56, 65, 66]. Eight patients overall $(8 / 237,3.4 \%)$ had a non-union during the follow-up period [37, 39, 44, 48, 66]. A total of 29 patients $(29 / 237,12.2 \%)$ required a revision operation $[1,16,21$, 37, 39, 41, 44, 48, 65, 66]. Three studies that principally used the anterior strategy reported a larger loss of correction during the follow-up period, which may be due to the poor stabilizing effect of the procedure [44, 48, 65].

Eight studies including 127 patients mainly used the anterior strategy for CK $[16,20,21,44,48,56,65,66]$. Seven patients in this cohort were treated with a combined anterior and posterior procedure [48, 65]. Two patients were lost to follow-up [56]. Two patients died at 4 and 20 days postoperatively, respectively [16, 20]. They were excluded from further study. Therefore, 116 patients were treated for $\mathrm{CK}$ with the anterior-alone procedure, of which 3 patients died at least 3 months after surgery and were included in the studies [16, 48, 65]. The overall mortality encompassing all 120 patients who were treated with anterior-alone procedure was 4.2\% (5/120) [16, 20, 48, 65]. Two patients $(2 / 116,1.72 \%)$ deteriorated neurologically after surgery $[16,21]$. One study focused on the complications in which there was no detailed information with regard to clinical and radiological evaluation [48]. Therefore, 101 patients in seven studies were evaluated radiologically $[16,20,21,44,56,65,66]$. The mean preoperative kyphosis was $26.5^{\circ}$, the mean postoperative kyphosis was $3.5^{\circ}$, and the mean correction angle was $23.0^{\circ}$. As much as 52 patients $(52 / 101,51.5 \%)$ achieved a correction that produced a neutral or lordotic alignment. Six patients $(6 / 116,5.2 \%)$ had a pseudarthrosis during the follow-up period [44, 48, 66]. Based on six studies including 95 patients $[16,20,21,44,56,65]$, there were 32 complications $(32 / 95,33.7 \%)$ (Table 4). Twelve (12/101, $11.9 \%$ ) patients underwent a reoperation for the treatment of the complications [16, 20, 21, 44, 56, 65, 66].

Six studies that included 111 patients introduced the combined anterior and posterior strategy for CK [1, 37, 39, 41, 48, 65]. Three patients were lost to follow-up and four patients died before adequate follow-up could be completed [37, 41]. They were excluded from further analysis in this study. Therefore, there were 104 patients in this study including three delayed deaths $[37,65]$. The overall mortality encompassing all 111 patients who were treated with the combined procedure was $6.3 \%$ (7/111). Six patients $(6 / 91,6.6 \%)$ [37, 39, 41, 48, 65] worsened neurologically, of which four patients presented with radicular symptoms and two patient developed quadriparesis or quadriplegia after surgery [39, 41]. Two patients (2/104, $1.92 \%$ ) had a pseudarthrosis during follow-up [37, 39]. Seventy-four patients in four studies were evaluated radiologically [1, 39, 41, 65]. The mean amount of preoperative kyphosis was $26.5^{\circ}$, the mean postoperative kyphosis was $-3.5^{\circ}$, and the mean correction degree was $30.0^{\circ}$. Based on four studies that included 92 patients [37, $39,41,65]$, there were 45 complications in 92 patients (45/92, 48.9\%) (Table 4). Eleven patients (11/88, 12.5\%) underwent revision surgery.

We compared the anterior strategy with the combined strategy with regard to neurological deterioration, degree of correction, rate of non-union, complications, revision rates and mortality (Table 5; Fig. 3). The combined anterior and posterior strategy resulted in a greater correction than the anterior strategy. It was also more likely to improve the

Table 4 Complications associated with the anterior and combined strategies

\begin{tabular}{|c|c|}
\hline $\begin{array}{l}\text { Surgical } \\
\text { strategy }\end{array}$ & Complications \\
\hline Anterior & $\begin{array}{l}\text { Based on six studies including } 95 \text { patients }[16,20,21,44,56,65] \text {, there were } 32 \text { complications }(32 / 95,33.7 \%) \text {. The } \\
\text { complications included dislodgments of the grafts }(4 / 95,4.2 \%) \text {, pseudoarthrosis }(1 / 95,1.1 \%) \text {, screw loosening }(3 / 95,3.2 \%) \text {, } \\
\text { vocal cord paresis }(5 / 95,5.3 \%) \text {, deaths }(n=4) \text {, pneumonia }(n=4) \text {, dysphagia }(n=3) \text {, neurological deterioration }(n=2) \text {, } \\
\text { infection }(n=2) \text {, dural tear }(n=1) \text {, deep venous thrombosis }(n=1) \text {, reintubation }(n=1) \text { and wound dehiscence }(n=1) \text {. } \\
\text { Five }(5 / 95,5.3 \%) \text { of the patients had graft-related complications and three }(3 / 95,3.2 \%) \text { had implant-related complications }\end{array}$ \\
\hline Combined & $\begin{array}{l}\text { Based on four studies that included } 92 \text { patients }[37,39,41,65] \text {, there were } 45 \text { complications in } 92 \text { patients }(45 / 92,48.9 \%) \text { The } \\
\text { complications included } 11(11 / 92,12.0 \%) \text { gastrostomy/tracheostomy, } 7(7 / 92,7.6 \%) \text { deaths, } 4(4 / 92,4.3 \%) \text { cases where there } \\
\text { was progression of the adjacent segment deformity, } 4(4 / 92,4.3 \%) \text { with radicular symptoms, wound dehiscences }(n=4) \text {, } \\
\text { hardware failures }(n=3) \text {, durotomy }(n=3) \text {, wound infections }(n=2) \text {, pseudoarthrosis }(n=2) \text {, quadriparesis }(n=1) \text {, } \\
\text { quadriplegia }(n=1) \text {, construct failure }(n=1) \text {, dysphonia }(n=1) \text { and transient dysphagia }(n=1)\end{array}$ \\
\hline
\end{tabular}


Table 5 Comparison between the anterior and combined strategies with regard to the clinical and radiological outcomes, as well as the associated complications

\begin{tabular}{llllllll}
\hline Surgical strategy & $\begin{array}{l}\text { Neurological } \\
\text { deterioration rate }(\%)\end{array}$ & $\begin{array}{l}\text { Correction } \\
\text { degree }\end{array}$ & $\begin{array}{l}\text { Postoperative } \\
\text { kyphosis }\end{array}$ & $\begin{array}{l}\text { Non-union } \\
\text { rate }(\%)\end{array}$ & $\begin{array}{l}\text { Comp. } \\
\text { rate }(\%)\end{array}$ & $\begin{array}{l}\text { Revision } \\
\text { rate }(\%)\end{array}$ & $\begin{array}{l}\text { Mortality } \\
(\%)\end{array}$ \\
\hline Anterior & 1.72 & $23.0^{\circ}$ & $3.5^{\circ}$ & 5.20 & 33.7 & 11.90 \\
Combined & 6.60 & $30.0^{\circ}$ & $-3.5^{\circ}$ & 1.92 & 48.9 & 12.50 \\
Total & 4.20 & $23.8^{\circ}$ & $2.4^{\circ}$ & 3.40 & 40.7 & 12.20 & 4.30 \\
\hline
\end{tabular}

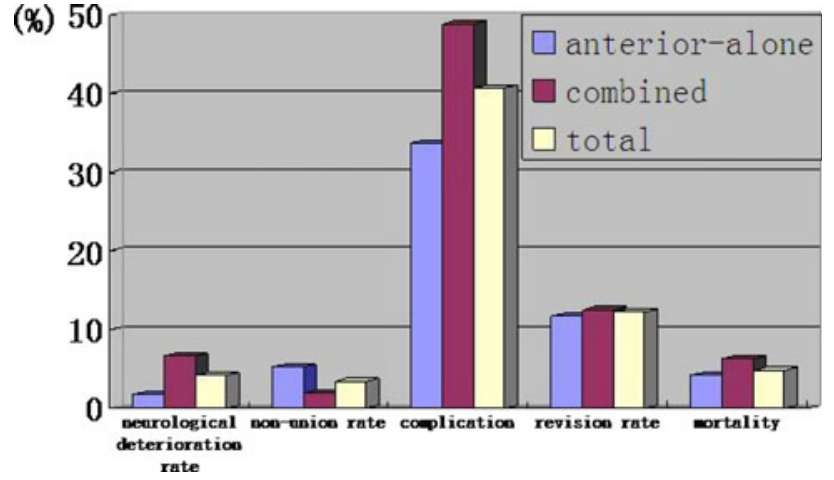

Fig. 3 A comparison between the anterior and combined strategies with regard to clinical and radiological outcomes, as well as complications

cervical alignment to achieve lordosis. However, the combined procedure involved a higher rate of postoperative neurological deterioration, complications, revision surgery and mortality. The main postsurgical neurological complication was radiculopathy, which was not present before surgery; this involved C5 nerve root palsy in particular, which was often related to posterior cervical surgical procedures. Postoperative quadriparesis was uncommon. The combined procedure had a lower rate of non-union due to its ability to achieve anterior and posterior stabilization, but it caused a higher rate of the need for a gastrostomy/tracheostomy secondary to airway and swallowing dysfunctions, which may be due to the stretching of the contracted esophagus and other neck structures during the larger correction of kyphosis. The more complicated procedures with more levels of reconstruction involved during the combined procedure may explain the higher rate of mortality and revision surgery, which comprised several interventions for wound healing problems. The anterior strategy achieved a smaller reduction of CK. However, this technique had a lower rate of postoperative neurological deterioration, complications, revision surgery and mortality. This may be because spinal surgeons are familiar with the anterior procedure, which is associated with fewer instances of neural injury. The anterior procedure had a higher rate of non-union after surgery, which may be due to the destabilization of cervical spine in the earlier stages of the procedure without internal fixation. Of the complications that were related to the anterior procedure, the most common were reconstruction related. Correspondingly, most revision surgeries were for salvage after the failure of reconstruction. The majority of deaths in the two strategies were related to medical comorbidities. Only two deaths were directly due to surgery.

\section{Conclusion}

Surgical management of CK should aim to achieve neural decompression, deformity correction and spinal reconstruction. Individualized approaches should be adopted based on the clinical and radiological evaluations, as well as on the morbidity and mortality risks of each surgical strategy. The retrospective design of previous studies potentially biases their results. Therefore, a multicenter, prospective, randomized, controlled study is necessary to determine the ideal mode of treatment for complex cervical kyphosis.

Conflict of interest No funds were received in support of this study.

\section{References}

1. Abumi K, Shono Y, Taneichi H, Ito M, Kaneda K (1999) Correction of cervical kyphosis using pedicle screw fixation systems. Spine 24:2389-2396

2. Albert TJ, Vacarro A (1998) Postlaminectomy kyphosis. Spine 23:2738-2745

3. Aronson DD, Kahn RH, Canady A, Bollinger RO, Towbin R (1991) Instability of the cervical spine after decompression in patients who have Arnold-Chiari malformation. J Bone Jt Surg Am 73:898-906

4. Belanger TA, Milam RA IV, Roh JS, Bohlman HH (2005) Cervicothoracic extension osteotomy for chin-on-chest deformity in ankylosing spondylitis. J Bone Jt Surg Am 87:1732-1738

5. Bell DF, Walker JL, O’Connor G, Tibshirani R (1994) Spinal deformity after multiple-level cervical laminectomy in children. Spine 19:406-411

6. Benzel EC (2001) Biomechanics of spine stabilization, 2nd edn. American Association of Neurological Surgeons, Park Ridge, pp 375-410

7. Breig A, El-Nadi AF (1966) Biomechanics of the cervical spinal cord. Relief of contact pressure on and overstretching of the spinal cord. Acta Radiol Diagn (Stockh) 4:602-624 
8. Butler JC, Whitecloud TS 3rd (1992) Postlaminectomy kyphosis. Causes and surgical management. Orthop Clin North Am 23:505-511

9. Caspar W, Pitzen T (1999) Anterior cervical fusion and trapezoidal plate stabilization for re-do surgery. Surg Neurol 52:345-352

10. Deen HG, Nottmeier EW, Reimer R (2006) Early complications of posterior rod-screw fixation of the cervical and upper thoracic spine. Neurosurgery 59:1062-1068

11. Epstein JA (1988) The surgical management of cervical spinal stenosis, spondylosis, and myeloradiculopathy by means of the posterior approach. Spine 13:864-869

12. Etame AB, Than KD, Wang AC, La Marca F, Park P (2008) Surgical management of symptomatic cervical or cervicothoracic kyphosis due to ankylosing spondylitis. Spine 33:E559-E564

13. Etame AB, Wang AC, Than KD, La Marca F, Park P (2010) Outcomes after surgery for cervical spine deformity: review of the literature. Neurosurg Focus 28:E14

14. Fassett DR, Clark R, Brockmeyer DL, Schmidt MH (2006) Cervical spine deformity associated with resection of spinal cord tumors. Neurosurg Focus 20:E2

15. Fehlings MG, Cooper PR, Errico TJ (1994) Posterior plates in the management of cervical instability: long-term results in 44 patients. J Neurosurg 81:341-349

16. Ferch RD, Shad A, Cadoux-Hudson TA, Teddy PJ (2004) Anterior correction of cervical kyphotic deformity: effects on myelopathy, neck pain, and sagittal alignment. J Neurosurg 100:13-19

17. Ganju A, Ondra SL, Shaffrey CI (2003) Cervical kyphosis. Tech Orthop 17:345-354

18. Geisler FH, Caspar W, Pitzen T, Johnson TA (1998) Reoperation in patients after anterior cervical plate stabilization in degenerative disease. Spine 23:911-920

19. Gore DR, Sepic SB, Gardner GM (1986) Roentgenographic findings of the cervical spine in asymptomatic people. Spine $11: 521-524$

20. Gülmen V, Zileli M (2000) Surgical treatment of postlaminectomy cervical kyphosis. Turk Neurosurg 10:28-35

21. Herman JM, Sonntag VK (1994) Cervical corpectomy and plate fixation for postlaminectomy kyphosis. J Neurosurg 80:963-970

22. Houten JK, Cooper PR (2003) Laminectomy and posterior cervical plating for multilevel cervical spondylotic myelopathy and ossification of the posterior longitudinal ligament: effects on cervical alignment, spinal cord compression, and neurological outcome. Neurosurgery 52:1081-1088

23. Iwasaki M, Yamamoto T, Miyauchi A, Amano K, Yonenobu K (2002) Cervical kyphosis: predictive factors for progression of kyphosis and myelopathy. Spine 27:1419-1425

24. Jones EL, Heller JG, Silcox DH, Hutton WC (1997) Cervical pedicle screws versus lateral mass screws: anatomic feasibility and biomechanical comparison. Spine 22:977-982

25. Kaptain GJ, Simmons N, Replogle RE, Pobereskin L (2000) Incidence and outcome of kyphotic deformity following laminectomy for cervical spondylotic myelopathy. J Neurosurg 93(Suppl 2):199-204

26. Katsumi Y, Honma T, Nakamura T (1989) Analysis of cervical instability resulting from laminectomies for removal of spinal cord tumor. Spine 14:1171-1176

27. Katsuura A, Hukuda S, Imanaka T, Miyamoto K, Kanemoto M (1996) Anterior cervical plate used in degenerative disease can maintain cervical lordosis. J Spinal Disord 9:470-476

28. King J, Stowe S (1982) Results of spinal fusion for radiation scoliosis. Spine 7:574-585

29. Kotani Y, Cunningham BW, Abumi K, McAfee PC (1994) Biomechanical analysis of cervical stabilization systems: an assessment of transpedicular screw fixation in the cervical spine. Spine 19:2529-2539

30. Lonstein JE (1977) Post-laminectomy kyphosis. Clin Orthop Relat Res 128:93-100

31. Lunardi P, Licastro G, Missori P, Ferrante L, Fortuna A (1993) Management of intramedullary tumors in children. Acta Neurochir (Wien) 120:59-65

32. Masini M, Maranhao V (1997) Experimental determination of the effect of progressive sharp-angle spinal deformity on the spinal cord. Eur Spine J 6:89-92

33. McAfee PC, Bohlman HH, Ducker TB, Zeidman SM, Goldstein JA (1995) One-stage anterior cervical decompression and posterior stabilization. A study of one hundred patients with a minimum of two years of follow-up. J Bone and Jt Surg Am 77:1791-1800

34. McLaughlin MR, Wahlig JB, Pollack IF (1997) Incidence of postlaminectomy kyphosis after Chiari decompression. Spine 22:613-617

35. McMaster MJ (1997) Osteotomy of the cervical spine in ankylosing spondylitis. J Bone Jt Surg Br 79:197-203

36. Mikaw Y, Shikata J, Tamamuro T (1987) Spinal deformity and instability after multilevel cervical laminectomy. Spine 12:6-11

37. Mummaneni PV, Dhall SS, Rodts GE, Haid RW (2008) Circumferential fusion for cervical kyphotic deformity. J Neurosurg Spine 9:515-521

38. Munechika Y (1973) Influence of laminectomy on the stability of the spine: an experimental study with special reference to the extent of laminectomy and the resection of the intervertebral joint. J Jpn Orthop Assoc 47:111-126

39. Nottmeier EW, Deen HG, Patel N, Birch B (2009) Cervical kyphotic deformity correction using 360-degree reconstruction. J Spinal Disord Tech 22:385-391

40. Nowinski GP, Visarius H, Nolte LP, Herkowitz HN (1993) A biomechanical comparison of cervical laminoplasty and cervical laminectomy with progressive facetectomy. Spine 18:1995-2004

41. O'Shaughnessy BA, Liu JC, Hsieh PC, Koski TR, Ganju A, Ondra SL (2008) Surgical treatment of fixed cervical kyphosis with myelopathy. Spine 33:771-778

42. Otsuka NY, Hey L, Hall JD (1998) Postlaminectomy and postirradiation kyphosis in children and adolescents. Clin Orthop Rel Res 354:189-194

43. Pal GP, Sherk HH (1988) The vertical stability of the cervical spine. Spine 13:447-449

44. Park Y, Riew KD, Cho W (2010) The long-term results of anterior surgical reconstruction in patients with postlaminectomy cervical kyphosis. The Spine Journal 10:380-387

45. Raimondi AJ, Gutierrez FA, DiRocco C (1976) Laminotomy and total reconstruction of the posterior spinal arch for spinal canal surgery in childhood. J Neurosurg 45:555-560

46. Ratliff JK, Cooper PR (2003) Cervical laminoplasty: a critical review. J Neurosurg 98(Suppl 3):230-238

47. Riew KD (1998) Microscope-assisted anterior cervical decompression and plating techniques for multilevel cervical spondylosis. Oper Tech Orthop 8:22-33

48. Riew KD, Hilibrand AS, Palumbo MA, Bohlman HH (1999) Anterior cervical corpectomy in patients previously managed with a laminectomy: short-term complications. $\mathrm{J}$ Bone and $\mathrm{Jt}$ Surg Am 81:950-957

49. Riseborough EJ (1977) Irradiation induced kyphosis. Clin Orthop Relat Res 128:101-106

50. Sagi HC, Beutler W, Carroll E, Connolly PJ (2002) Airway complications associated with surgery on the anterior cervical spine. Spine 27:949-953

51. Schultz KD Jr, Mclaughlin MR, Haid RW Jr, Comey CH, Rodts GE Jr, Alexander J (2000) Single-stage anterior-posterior 
decompression and stabilization for complex cervical spine disorders. J Neurosurg 93(Suppl 2):214-221

52. Sciubba DM, Chaichana KL, Woodworth GF, McGirt MJ, Gokaslan ZL, Jallo GI (2008) Factors associated with cervical instability requiring fusion after cervical laminectomy for intradural tumor resection. J Neurosurg Spine 8:413-419

53. Shimizu K, Nakamura M, Nishikawa Y, Hijikata S, Chiba K, Toyama Y (2005) Spinal kyphosis causes demyelination and neuronal loss in the spinal cord. Spine 30:2388-2392

54. Sim FH, Svien HJ, Bickel WH, Janes JM (1974) Swan-neck deformity following extensive cervical laminectomy. A review of twenty-one cases. J Bone Jt Surg Am 56:564-580

55. Spivak J, Giordano CP (1997) Cervical kyphosis. In: Bridwell KH, DeWald RL (eds) The textbook of spinal surgery, 2nd edn. Lippincott-Raven, Philadelphia, pp 1027-1038

56. Steinmetz MP, Kager CD, Benzel EC (2003) Ventral correction of postsurgical cervical kyphosis. J Neurosurg 98(Suppl 1):1-7

57. Steinmetz MP, Stewart TJ, Kager CD, Benzel EC, Vaccaro AR (2007) Cervical deformity correction. Neurosurgery 60(Suppl 1): S90-S97

58. Stewart TJ, Steinmetz MP, Benzel EC (2005) Techniques for the ventral correction of postsurgical cervical kyphotic deformity. Neurosurgery 56(Suppl 1):191-195

59. Tachdjian MO, Matson DD (1965) Orthopaedic aspects of intraspinal tumors in infants and children. J Bone Jt Surg Am 47:223-248
60. Vollmer DG, Arnold PM, Maiman DJ (1999) Subaxial cervical deformities. In: Benzel EC (ed) Spine surgery: techniques, complication avoidance and management. Churchill Livingstone, Philadelphia, pp 229-240

61. White AA III, Panjabi MM (1988) Biomechanical considerations in the surgical management of cervical spondylotic myelopathy. Spine 13:856-860

62. Yasuoka S, Peterson HA, Laws ER Jr, MacCarty CS (1981) Pathogenesis and prophylaxis of postlaminectomy deformity of the spine after multiple level laminectomy: difference between children and adults. Neurosurgery 9:145-152

63. Yasuoka S, Peterson HA, MacCarty CS (1982) Incidence of spinal column deformity after multilevel laminectomy in children and adults. J Neurosurg 57:441-445

64. Zdeblick TA, Abitbol JJ, Kunz DN, McCabe RP, Garfin S (1993) Cervical stability after sequential capsule resection. Spine 18:20052008

65. Zdeblick TA, Bohlman HH (1989) Cervical kyphosis and myelopathy. Treatment by anterior corpectomy and strut-grafting. J Bone and Jt Surg Am 71:170-182

66. Zdeblick TA, Hughens SS, Riew KD, Bohlman HH (1997) Failed anterior cervical discectomy and arthrodesis. Analysis and treatment of thirty-five patients. J Bone and Jt Surg Am 79:523-532 